\title{
A CATALOGUE OF THE ASCIDIAN TYPE - SPECIMENS IN THE AUSTRALIAN MUSEUM, SYDNEY
}

\author{
FRANCIS W. E. ROWE AND JANET I. MARSHALL \\ The Australian Museum, Sydney
}

\begin{abstract}
SUMMARY
Nearly 400 type-specimens representing 137 currently-recognised species of ascidians are listed. The majority of these species have been described by Patricia Kott and W. A. Herdman, and are from Australian waters.
\end{abstract}

\section{INTRODUCTION}

The ascidian type-collection in the Australian Museum presently comprises about 384 specimens, representing 155 nominal species, of which about 137 are currently recognised. Of the 155 nominal species, 82 have been described by Kott since 1952; 57 were described by Herdman $(1899), 6$ by Michaelsen $(1898,1900) 3$ by Herdman and Riddell (1913), 3 by Kesteven (1909) and 2 each by Hastings (1931) and Brewin $(1953,1956)$.

Of the currently-recognised species, 123 were collected from around the coasts of Australia, 10 are from the Antarctic and 4 from the South Atlantic. Collections from the Australian coasts appear to include types of at least $60 \%$ of the known Australian fauna as recognised by Kott (1974). However, Kott only lists distributions for 71 of the species represented in the Australian Museum collections. Of these, 55 are considered by Kott (1974) to be endemic, mostly with a temperate distribution.

Fifty-two species not discussed by Kott (1974) also appear to be endemic, occurring almost entirely in temperate waters. Kott (1974) considered the Australian fauna to comprise about 200 species of which she dealt with 180 in her paper. Considering the number of species housed in the Australian Museum not considered by Kott, and allowing for new species described since 1974, it can be projected that, at the time of writing, about 250 species of ascidian are known to occur around the coasts of Australia, of which $60 \%$ are likely to be endemic.

Without doubt Kott is the most prolific Australian ascidian taxonomist and, therefore, is responsible for most of the descriptions and synonymies. Often, however, particularly prior to 1962, Kott did not designate type-specimens in her descriptions of new species. The type specimens are known to be housed in the Australian Museum (Kott, pers. comm.). Consequently, where only one specimen is recorded and is in this collection, this specimen is considered to be the holotype (Article 73(a) I.C.Z.N.). If several specimens are recorded in the literature, but there is no clear indication that the description has been based on a single specimen, then specimens held in the museum are considered to form a syntype-series. In recent reports, specimens other than that listed by Kott as the holotype are recorded here as paratypes.

With regard to "colonial" and "compound" species, each type specimen is considered as a single entity, regardless of the number of "heads" or "lobes" it may possess, unless originally broken up and separately labelled by the author of the species.

Entries in this catalogue are arranged alphabetically by original species or subspecies name. Where the genus - or the species - name has subsequently changed, the new name is also given, together with a reference to the source of the change.

Australian Museum catalogue numbers are prefaced by the letters " $U$ ", " $G$ ", " $Y$ " or " $Z$ ", " $Y$ " being the current registration letter.

Records of The Australian Museum, 1979, Vol. 32, No. 17, 547-562 